\title{
Tumor Necrosis Factor and Regulatory T Cells
}

\author{
Min Kyung Jung ${ }^{1}$, Jeong Seok Lee ${ }^{1}$, Jeong-Eun Kwak², and Eui-Cheol Shin ${ }^{1,2}$ \\ ${ }^{1}$ Laboratory of Immunology and Infectious Diseases, Graduate School of Medical Science and Engineering, Korea Advanced Institute of Science \\ and Technology, Daejeon; \\ ${ }^{2}$ BioMedical Science and Engineering Interdisciplinary Program, Korea Advanced Institute of Science and Technology, Daejeon, Korea.
}

$\mathrm{CD}^{+} \mathrm{CD}^{2} 5^{+} \mathrm{FoxP}^{+}$regulatory $\mathrm{T}$ (Treg) cells play major roles in the maintenance of immune homeostasis. In this review, we comprehensively describe the relationship between tumor necrosis factor (TNF) and Treg cells, focusing on the effects of TNF on Treg cells and on TNF-producing Treg cells. Contradictory results have been reported for the effect of TNF on the suppressive activity of Treg cells. In patients with rheumatoid arthritis, TNF has been shown to reduce the suppressive activity of Treg cells. Meanwhile, however, TNF has also been reported to maintain the suppressive activity of Treg cells via a TNFR2-mediated mechanism. In addition, Treg cells have been found to acquire the ability to produce TNF under inflammatory conditions, such as acute viral hepatitis. These TNF-producing Treg cells exhibit $\mathrm{T}$ helper 17 -like features and hold significance in various human diseases.

Key Words: Tumor necrosis factor, regulatory T cell, inflammation, TNFR2

\section{INTRODUCTION}

$\mathrm{CD}^{+} \mathrm{CD}^{+} 5^{+} \mathrm{FoxP}^{+}$regulatory $\mathrm{T}$ (Treg) cells are specialized $\mathrm{T}$ cells involved in the maintenance of immune homeostasis, and their dysregulation is involved in various autoimmune and inflammatory diseases. In many inflammatory diseases, tumor necrosis factor (TNF) is produced by various immune cells, including activated macrophages, monocytes, and $\mathrm{T}$ cells. However, the interactions between TNF and Treg cells have not been clearly elucidated. ${ }^{1}$ Though some studies have suggested that TNF enhances the suppressive function of Treg cells, ${ }^{2-4}$ others have shown that TNF reduces the suppressive function of Treg cells. ${ }^{5-7}$

Under inflammatory conditions, Treg cells that stably express FoxP3 acquire the ability to produce pro-inflammatory cytokines. Treg cells that produce pro-inflammatory cytokines

Received: August 16, 2018 Revised: November 17, 2018

Accepted: November 17, 2018

Corresponding author: Eui-Cheol Shin, MD, PhD, Laboratory of Immunology and Infectious Diseases, Graduate School of Medical Science and Engineering, Korea Advanced Institute of Science and Technology, 291 Daehak-ro, Daejeon 34141 Korea.

Tel: 82-42-350-4236, Fax: 82-42-350-4240, E-mail: ecshin@kaist.ac.kr

-The authors have no potential conflicts of interest to disclose.

(C) Copyright: Yonsei University College of Medicine 2019

This is an Open Access article distributed under the terms of the Creative Commons Attribution Non-Commercial License (https://creativecommons.org/licenses/ by-nc/4.0) which permits unrestricted non-commercial use, distribution, and reproduction in any medium, provided the original work is properly cited. are referred to as T helper (Th)-like Treg cells. These cells express lineage-specific transcription factors and chemokine receptors. ${ }^{8,9}$ Th1-like Treg cells produce IFN- $\gamma$ and express T-bet and CXCR3, which are Th1-specific molecules. ${ }^{8,10}$ Th17-like Treg cells produce IL-17A and express STAT3, ROR $\gamma \mathrm{t}$, and CCR6, which are Th17-specific molecules.,11 Th1- and Th17like Treg cells have been proposed to suppress Thl and Th17 effector $\mathrm{T}$ cell responses, respectively, via tissue migration mediated by specific chemokine receptors, such as CXCR3 and CCR6. ${ }^{8-11}$ Meanwhile, however, Th1- or Th17-like Treg cells have also been suggested to be involved in the pathogenesis of autoimmune and inflammatory diseases. ${ }^{12}$ We recently reported that Treg cells can produce TNF in patients with acute viral hepatitis and that TNF-producing Treg cells exhibited Th17-like features. ${ }^{13}$

In this review, we describe the effects of TNF on Treg cells and TNF-producing Treg cells and the possible implications of this interaction in various human diseases.

\section{TUMOR NECROSIS FACTOR}

TNF is a pro-inflammatory cytokine first discovered as an endotoxin-induced factor in $1975 .^{14}$ TNF plays a role in septic shock, cachexia, and the pathogenesis of various autoimmune and inflammatory diseases. TNF is produced by monocytes and macrophages, as well as other immune cells, in- 
cluding dendritic cells, B cells, activated natural killer cells, and activated T cells. ${ }^{15,16}$ When exogenous or endogenous stimuli induce the production of TNF, it is initially expressed on the cell surface in membrane-bound form (mTNF, 26 $\mathrm{kDa}$ ), which is then cleaved by a metalloproteinase, TNF $\alpha$ converting enzyme (TACE), and released as soluble TNF (sTNF, $17 \mathrm{kDa}) .{ }^{17,18}$

TNF has two cell membrane receptors, TNFR1 (p55) and TNFR2 (p75). TNFR1 is a major TNF receptor ubiquitously expressed on most cell types. TNFR1 binding to either mTNF or sTNF leads to recruitment and clustering of TNF receptorassociated factor (TRAF), TNFR-associated death domain (TRADD), and receptor-interacting protein-1 (RIP1). ${ }^{19-21}$ This complex activates activator protein-1 (AP-1), mitogen-activated protein kinases (MAPKs), and nuclear factor $\kappa$-light-chainenhancer of activated B cells (NF- $\mathrm{B})$, which are important factors in the expression of multiple inflammatory cytokines. TNFR1 can also activate another signaling pathway: the TNFR1 signaling complex can recruit FAS-associated death domain protein (FADD), which activates apoptotic caspase cascades and the pro-apoptotic protein BH3 interacting domain death agonist (BID). ${ }^{22,23}$

The expression of TNFR2 is restricted to immune cells ${ }^{24}$ and binds with higher affinity to mTNF than sTNF. ${ }^{25}$ Binding of TNF to TNFR2 recruits TRAF1, 2, and 3, as well as cellular inhibitor of apoptosis proteins $1 / 2$ (cIAP1/2). TNFR2 does not possess a death domain and its activation results in different signaling than TNFR1. The downstream signals of TNFR2 activate both the canonical and non-canonical NF-kB pathways, ${ }^{26,27}$ as well as the phosphoinositide 3-kinase (PI3K)-protein kinase B (Akt) signaling pathway directly related to survival and cell proliferation. Interestingly, TNFR2 is more highly expressed on Treg cells, compared to non-Treg effector T cells, ${ }^{28}$ whereas TNFR1 expression is not different between Treg and non-Treg CD4 ${ }^{+}$T cells. ${ }^{29}$ TNFR2 is upregulated in a suppressive subset of Treg cells ${ }^{2}$ and is required for the stabilization of Treg cells in the murine system. ${ }^{24}$ In humans, TNFR2 ${ }^{+}$Treg cells express higher levels of CTLA-4, which is involved in the suppressive activity of Treg cells, compared to TNFR2- Treg cells and non-Treg CD4 ${ }^{+}$T cells. ${ }^{28}$ Furthermore, TNFR2 may play a role in the suppressive activity of Treg cells, although the underlying mechanisms have only recently begun to be clarified.

\section{EFFECTS OF TNF ON REGULATORYT CELLS}

Successful treatment of several inflammatory disorders, such as rheumatoid arthritis (RA), ankylosing spondylitis, psoriasis, and vasculitis, with anti-TNF agents suggests the importance of TNF in inflammatory processes in the human immune system. As a bridging cytokine between innate and adaptive immune responses in inflammation, TNF exerts pleiotropic ef- fects on Treg cells.

Treg cells in patients with autoimmune diseases are exposed to the inflammatory milieu, including TNF, which is provided by various immune cells. At a highly pro-inflammatory site, such as the synovial fluid of RA patients, TNF produced by activated monocytes diminishes the suppressive activity of Treg cells and contributes to chronic inflammation:? the direct effect of TNF on Treg cells has been investigated primarily in RA patients. TNF appears to suppress the function of Treg cells in RA patients by reducing FoxP3 expression. ${ }^{6}$ Interestingly, the anti-TNF antibody infliximab was found to restore the reduced FoxP3 expression in RA patients. ${ }^{6}$ Another study demonstrated that TNF activates the canonical $\mathrm{NF}-\kappa \mathrm{B}$ pathway and disturbs the suppressive function in human Treg cells, particularly for the CD45RA- population, though FoxP3 levels remain stable. ${ }^{5}$ Restoration of the compromised function of Treg cells in RA patients by anti-TNF treatment also suggests that TNF down-regulates the suppressive function of Treg cells. ${ }^{1}$

While the negative effects of TNF on Treg cell function and proliferation were reported first, recent studies have shown contrasting effects for TNF on the function of Treg cells. In healthy human subjects, the suppressive activity of Treg cells was maintained after exposure to TNF in vitro. ${ }^{30} \mathrm{~A}$ murine model of graft versus host disease also showed that TNF enhances the suppressive function of Treg cells but does not change the function of non-Treg $\mathrm{CD} 4^{+} \mathrm{T}$ cells. ${ }^{4}$ The positive effect of TNF on Treg cell function was further supported by TNF-deficient mice developing prolonged and exacerbated experimental autoimmune encephalomyelitis. ${ }^{31}$ TNFR2-mediated signaling was also recently reported to be important in the effect of TNF on Treg cells: ${ }^{32}$ TNFR2 is expressed in the subpopulation of Treg cells with superior suppressive ability. In addition, TNFR2 has been shown to stabilize the phenotype and function of Treg cells in a murine model, ${ }^{24}$ even in a highly inflammatory environment, which destabilizes FoxP3 expression in Treg cells.

TNFR2 is expressed on suppressive Treg cells, and it has been used to isolate suppressive Treg cells for therapeutic application. ${ }^{2,33,34}$ In addition, as mTNF effectively stimulates TNFR2, ${ }^{35}$ a method was developed for mTNF-induced stimulation of isolated Treg cells for immunosuppressive therapy. ${ }^{36}$ Chemical agonists of TNFR2 have also been used for the selective expansion of suppressive Treg cells. ${ }^{37}$

The effect of TNF on Treg cells in tumor tissues was reported recently. TNF induced proliferation of Treg cells at tumor sites via TNFR2, and TNFR2 ${ }^{+}$Treg cells enhanced the escape of tumor cells from immune surveillance.$^{38}$ In the B16F10 murine model of metastatic melanoma, TNF was shown to activate Treg cells and expand the suppressive subpopulation. Silencing of TNF or TNFR2 expression reversed the immunotolerant tumor microenvironment to prevent metastasis. ${ }^{39}$ Meanwhile, increased expression of TNFR2 among Treg cells 
was observed in malignant ascites from ovarian cancer patients. ${ }^{40}$ Thus, TNFR2 ${ }^{+}$Treg cells can be targeted to enhance anti-tumor immune responses.

Analysis of Treg cells in patients undergoing anti-TNF treatment has provided understanding of the effect of TNF on Treg cells. Decreased function of Treg cells has been reported in RA patients, as well as its reversal by anti-TNF agents. ${ }^{31,41}$ More than a decade after the first clinical use of anti-TNF agents in humans, the mechanism underlying the restorative effect of anti-TNF agents on Treg cells was discovered. ${ }^{42}$ Anti-TNF antibody adalimumab was found to promote the interaction of monocytes and Treg cells and to expand Treg cells, particularly via TNFR2. ${ }^{42}$ Considering the positive role of TNF signaling via TNFR2 on Treg cells with respect to immunomodulation, selective blocking antibodies against TNFR1 have been tested in a murine collagen-induced arthritis model and primary cell culture obtained from the synovial tissues of RA patients with positive results. ${ }^{43,44}$ Anti-TNF agents rarely induce unexpected, so-called 'paradoxical' exacerbation of autoimmune diseases, such as psoriasis. ${ }^{31}$ A study in the murine psoriasis model has shown that the disturbance of Treg cells and relative expansion of the Th17 population contribute to the paradoxical exacerbation. ${ }^{45}$

\section{TNF-PRODUCING REGULATORY T CELLS}

Treg cells typically produce anti-inflammatory cytokines, such as IL-10, TGF- $\beta$, and IL-35, which are involved in the suppressive function of Treg cells; however, they can also produce pro-inflammatory cytokines under certain inflammatory conditions. ${ }^{46-48}$ Treg cells have been found to produce IFN- $\gamma$ in patients with multiple sclerosis and type I diabetes, ${ }^{49,50}$ and IL-17A in patients with Crohn's disease and RA., ${ }^{9,51-57}$ These inflammatory Treg cells may be involved in the pathogenesis of autoimmune and inflammatory diseases. ${ }^{12}$ During microbial infection, inflammatory Treg cells may contribute to the elimination of microbial pathogens by secreting pro-inflammatory cytokines. However, they may also enhance inflammation and exacerbate host injury during infection.

A study investigating RA suggested that memory Treg cells $\left(\mathrm{CD} 4^{+} \mathrm{CD} 45 \mathrm{RO}^{+} \mathrm{CD} 25^{+} \mathrm{CD} 127^{\text {low }}\right)$ acquire the ability to produce pro-inflammatory cytokines, including not only IFN- $\gamma$ and IL17 , but also TNF, in response to inflammatory stimuli. ${ }^{58}$ These Treg cells maintain their suppressive capacity. In addition, Treg cells from healthy donors appeared to acquire the ability to produce pro-inflammatory cytokines, including TNF, in coculture with autologous monocytes activated by lipopolysaccharide. These data suggest that activated monocytes potently induce the production of pro-inflammatory cytokines by Treg cells.

Another recent study reported that Treg cells from patients with acute hepatitis A (AHA) produce pro-inflammatory cytokines in direct ex vivo assays. ${ }^{13}$ A high proportion of Treg cells in the peripheral blood of patients with AHA produced TNF, and TNF-producing Treg cells were associated with severe liver injury, indicating that TNF-producing Treg cells are involved in the process of immune-mediated liver injury during AHA (Fig. 1). TNF-producing Treg cells from AHA patients were confirmed to be bona fide Treg cells, not activated T cells transiently expressing Foxp3, based on hypo-methylation at the Treg-specific demethylated region. ${ }^{4}$ TNF-producing Treg cells from patients with AHA exhibited features of Th17-like cells, as characterized by up-regulation of ROR $\gamma \mathrm{t}$, CCR6, and

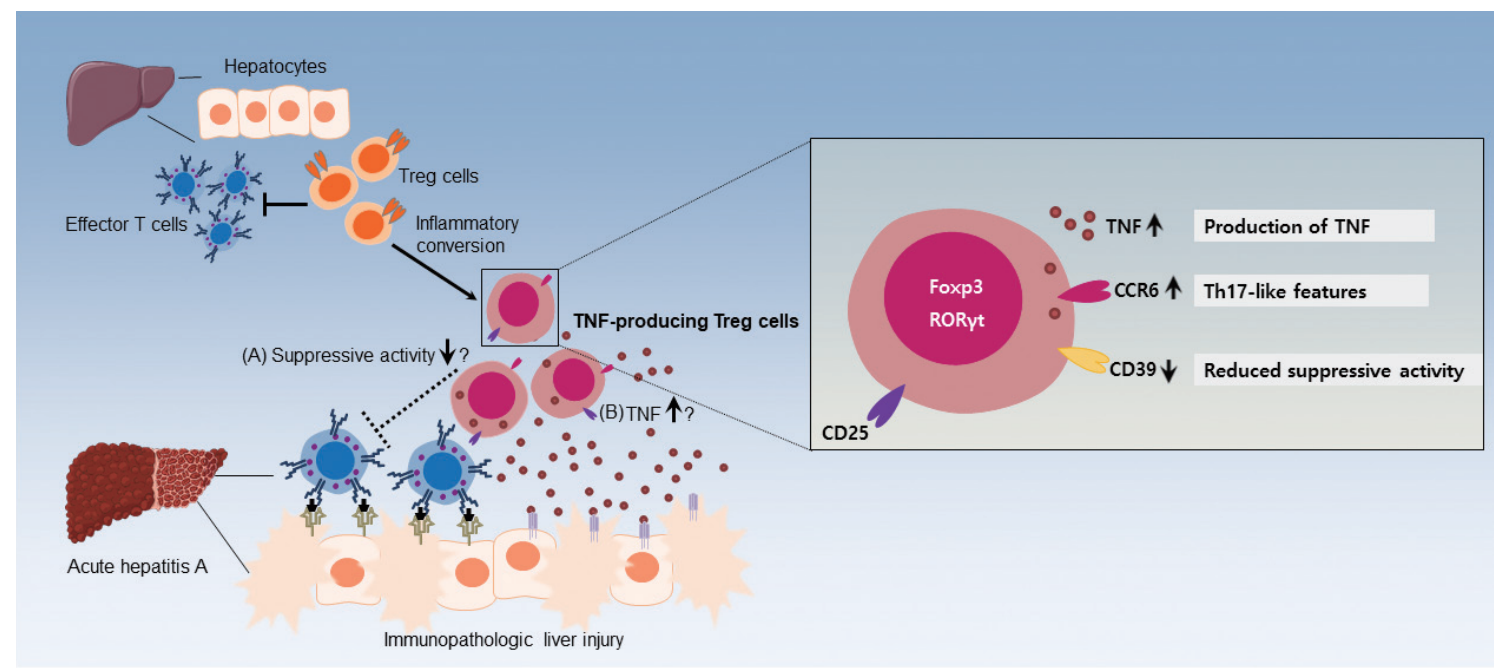

Fig. 1. TNF-producing Treg cells in AHA patients. Treg cells from AHA patients produce TNF and exhibit reduced suppressive activity due to inflammatory conversion. In AHA patients, TNF-producing Treg cells are associated with severe liver injury mediated by immunopathologic mechanisms. Two possible mechanisms have been proposed to explain how TNF-producing Treg cells are involved in liver injury. (A) First, the reduced suppressive activity of TNFproducing Treg cells may lead to unchecked activation of effector T cells, which contributes to liver injury. (B) Second, TNF produced by Treg cells may directly contribute to liver injury. The magnified figure on the right shows the phenotypic characteristics of TNF-producing Treg cells. TNF, tumor necrosis factor; AHA, acute hepatitis A; Treg, regulatory T. 
IL-17A. Importantly, ROR $\gamma \mathrm{t}$ inhibition decreased the production of TNF by Treg cells, indicating that TNF is produced by Treg cells from AHA patients in a ROR $\gamma \mathrm{t}$-dependent manner.

TNF-producing Treg cells from AHA patients have been shown to express low levels of CD39 (ectonucleoside triphosphate diphosphohydrolase-1), which contributes to the suppressive activity of Treg cells. Treg cells from AHA patients have reduced suppressive functions, compared to Treg cells from healthy individuals. However, blockade of TNF does not restore the suppressive activity of Treg cells, indicating that TNF itself is not responsible for the reduced suppressive functions of Treg cells from AHA patients. ${ }^{13}$ Interestingly, the relative frequency of TNF-producing Treg cells in peripheral blood is also increased in patients with other inflammatory liver diseases, including chronic hepatitis B and C and toxic/ drug-induced hepatitis. ${ }^{13}$

\section{CONCLUSIONS}

Here, we reviewed the relationship between TNF and Treg cells in regards to the effects of TNF on Treg cells and TNFproducing Treg cells. TNF is a pleiotropic cytokine reported to exert a variety of effects on Treg cells. TNF downregulates the suppressive function of Treg cells in co-culture, ${ }^{6}$ but inconsistently increases the suppressive function of Treg cells and promotes their proliferation under certain circumstances. ${ }^{2,59,60}$ Whether these discrepancies can be attributed to the microenvironment in which Treg cells meet TNF remains unclear.

Treg cells produce TNF under specific disease-related inflammatory conditions. The functions of TNF-producing Treg cells depend on environmental cues, and further investigation is needed to determine the specific characteristics of TNFproducing Treg cells and related mechanisms. Understanding the detailed mechanism underlying how Treg cells produce TNF and the pathological role of these cells in human disease is important, as these cells may serve as therapeutic targets for the treatment of various inflammatory diseases.

\section{ACKNOWLEDGEMENTS}

This study was supported by grants from the National Research Foundation (NRF-2017R1A2A1A17069782) and the Korea Healthcare Technology R\&D Project (HI17C0176).

\section{AUTHOR CONTRIBUTIONS}

Wrote the first draft of the manuscript: Min Kyung Jung, Jeong Seok Lee, and Jeong-Eun Kwak. Approved the final version: Min Kyung Jung and Eui-Cheol Shin. Each author has participated sufficiently in the work to take public responsibility for appropriate portions of the content.

\section{ORCID iDs}

Min Kyung Jung https://orcid.org/0000-0003-2480-9202 Jeong Seok Lee https://orcid.org/0000-0001-8261-7044 Jeong-Eun Kwak https://orcid.org/0000-0003-3178-0823 Eui-Cheol Shin https://orcid.org/0000-0002-6308-9503

\section{REFERENCES}

1. Ehrenstein MR, Evans JG, Singh A, Moore S, Warnes G, Isenberg DA, et al. Compromised function of regulatory T cells in rheumatoid arthritis and reversal by anti-TNFalpha therapy. J Exp Med 2004;200:277-85.

2. Chen X, Subleski JJ, Kopf H, Howard OM, Männel DN, Oppenheim JJ. Cutting edge: expression of TNFR2 defines a maximally suppressive subset of mouse $\mathrm{CD}^{+} \mathrm{CD} 25^{+} \mathrm{FoxP}^{+} \mathrm{T}$ regulatory cells: applicability to tumor-infiltrating $\mathrm{T}$ regulatory cells. J Immunol 2008;180:6467-71.

3. Chen X, Oppenheim JJ. TNF-alpha: an activator of $\mathrm{CD}^{+}{ }^{+} \mathrm{FoxP}^{+}$ TNFR2 $^{+}$regulatory T cells. Curr Dir Autoimmun 2010;11:119-34.

4. Pierini A, Strober W, Moffett C, Baker J, Nishikii H, Alvarez M, et al. TNF- $\alpha$ priming enhances $\mathrm{CD} 4^{+} \mathrm{FoxP}^{+}$regulatory T-cell suppressive function in murine GVHD prevention and treatment. Blood 2016;128:866-71.

5. Nagar M, Jacob-Hirsch J, Vernitsky H, Berkun Y, Ben-Horin S, Amariglio N, et al. TNF activates a NF-kappaB-regulated cellular program in human CD45RA- regulatory T cells that modulates their suppressive function. J Immunol 2010;184:3570-81.

6. Valencia X, Stephens G, Goldbach-Mansky R, Wilson M, Shevach EM, Lipsky PE. TNF downmodulates the function of human CD4+CD25hi T-regulatory cells. Blood 2006;108:253-61.

7. van Amelsfort JM, van Roon JA, Noordegraaf M, Jacobs KM, Bijlsma JW, Lafeber FP, et al. Proinflammatory mediator-induced reversal of CD4+,CD25+ regulatory T cell-mediated suppression in rheumatoid arthritis. Arthritis Rheum 2007;56:732-42.

8. Stock P, Akbari O, Berry G, Freeman GJ, Dekruyff RH, Umetsu DT. Induction of Thelper type 1-like regulatory cells that express Foxp3 and protect against airway hyper-reactivity. Nat Immunol 2004; 5:1149-56.

9. Voo KS, Wang YH, Santori FR, Boggiano C, Wang YH, Arima K, et al. Identification of IL-17-producing FOXP3+ regulatory T cells in humans. Proc Natl Acad Sci U S A 2009;106:4793-8.

10. Koch MA, Tucker-Heard G, Perdue NR, Killebrew JR, Urdahl KB, Campbell DJ. The transcription factor T-bet controls regulatory $\mathrm{T}$ cell homeostasis and function during type 1 inflammation. Nat Immunol 2009;10:595-602.

11. Chaudhry A, Rudra D, Treuting P, Samstein RM, Liang Y, Kas A, et al. CD4+ regulatory T cells control TH17 responses in a Stat3-dependent manner. Science 2009;326:986-91.

12. Zhou X, Bailey-Bucktrout S, Jeker LT, Bluestone JA. Plasticity of CD4(+) FoxP3(+) T cells. Curr Opin Immunol 2009;21:281-5.

13. Choi YS, Jung MK, Lee J, Choi SJ, Choi SH, Lee HW, et al. Tumor necrosis factor-producing T-regulatory cells are associated with severe liver injury in patients with acute hepatitis A. Gastroenterology 2018;154:1047-60.

14. Carswell EA, Old LJ, Kassel RL, Green S, Fiore N, Williamson B. An endotoxin-induced serum factor that causes necrosis of tumors. Proc Natl Acad Sci U S A 1975;72:3666-70.

15. Turner M, Feldmann M. Comparison of patterns of expression of tumour necrosis factor, lymphotoxin and interleukin-6 mRNA. Biochem Biophys Res Commun 1988;153:1144-51.

16. Kelker HC, Oppenheim JD, Stone-Wolff D, Henriksen-DeStefano 
D, Aggarwal BB, Stevenson HC, et al. Characterization of human tumor necrosis factor produced by peripheral blood monocytes and its separation from lymphotoxin. Int J Cancer 1985;36:69-73.

17. Pennica D, Nedwin GE, Hayflick JS, Seeburg PH, Derynck R, Palladino MA, et al. Human tumour necrosis factor: precursor structure, expression and homology to lymphotoxin. Nature 1984;312: 724-9.

18. Black RA, Rauch CT, Kozlosky CJ, Peschon JJ, Slack JL, Wolfson $\mathrm{MF}$, et al. A metalloproteinase disintegrin that releases tumournecrosis factor-alpha from cells. Nature 1997;385:729-33.

19. Brenner D, Blaser H, Mak TW. Regulation of tumour necrosis factor signalling: live or let die. Nat Rev Immunol 2015;15:362-74.

20. Hsu H, Shu HB, Pan MG, Goeddel DV.TRADD-TRAF2 and TRADDFADD interactions define two distinct TNF receptor 1 signal transduction pathways. Cell 1996;84:299-308.

21. Hsu H, Xiong J, Goeddel DV. The TNF receptor 1-associated protein TRADD signals cell death and NF-kappa B activation. Cell 1995;81:495-504.

22. Wilson NS, Dixit V, Ashkenazi A. Death receptor signal transducers: nodes of coordination in immune signaling networks. Nat Immunol 2009;10:348-55.

23. Heinrich M, Neumeyer J, Jakob M, Hallas C, Tchikov V, WinotoMorbach S, et al. Cathepsin D links TNF-induced acid sphingomyelinase to Bid-mediated caspase-9 and -3 activation. Cell Death Differ 2004;11:550-63.

24. Chen X, Wu X, Zhou Q, Howard OM, Netea MG, Oppenheim JJ. TNFR2 is critical for the stabilization of the CD4+Foxp3+ regulatory $\mathrm{T}$ cell phenotype in the inflammatory environment. J Immunol 2013;190:1076-84.

25. Grell M, Douni E, Wajant H, Löhden M, Clauss M, Maxeiner B, et al. The transmembrane form of tumor necrosis factor is the prime activating ligand of the $80 \mathrm{kDa}$ tumor necrosis factor receptor. Cell 1995;83:793-802.

26. Rauert H, Wicovsky A, Müller N, Siegmund D, Spindler V, Waschke J, et al. Membrane tumor necrosis factor (TNF) induces p100 processing via TNF receptor-2 (TNFR2). J Biol Chem 2010; 285:7394-404.

27. Sun SC, Ley SC. New insights into NF-kappaB regulation and function. Trends Immunol 2008;29:469-78.

28. Chen X, Subleski JJ, Hamano R, Howard OM, Wiltrout RH, Oppenheim JJ. Co-expression of TNFR2 and CD25 identifies more of the functional CD4+FOXP3+ regulatory T cells in human peripheral blood. Eur J Immunol 2010;40:1099-106.

29. Okubo Y, Mera T, Wang L, Faustman DL. Homogeneous expansion of human T-regulatory cells via tumor necrosis factor receptor 2. Sci Rep 2013;3:3153.

30. Zaragoza B, Chen X, Oppenheim JJ, Baeyens A, Gregoire S, Chader $\mathrm{D}$, et al. Suppressive activity of human regulatory T cells is maintained in the presence of TNF. Nat Med 2016;22:16-7.

31. Kassiotis G, Kollias G. Uncoupling the proinflammatory from the immunosuppressive properties of tumor necrosis factor (TNF) at the p55 TNF receptor level: implications for pathogenesis and therapy of autoimmune demyelination. J Exp Med 2001;193:427-34.

32. Chen X, Oppenheim JJ. Contrasting effects of TNF and anti-TNF on the activation of effector $\mathrm{T}$ cells and regulatory $\mathrm{T}$ cells in autoimmunity. FEBS Lett 2011;585:3611-8.

33. Chopra M, Biehl M, Steinfatt T, Brandl A, Kums J, Amich J, et al. Exogenous TNFR2 activation protects from acute GvHD via host T reg cell expansion. J Exp Med 2016;213:1881-900.

34. Leclerc M, Naserian S, Pilon C, Thiolat A, Martin GH, Pouchy C, et al. Control of GVHD by regulatory T cells depends on TNF produced by T cells and TNFR2 expressed by regulatory T cells. Blood 2016;128:1651-9.
35. Hu X, Li B, Li X, Zhao X, Wan L, Lin G, et al. Transmembrane TNF- $\alpha$ promotes suppressive activities of myeloid-derived suppressor cells via TNFR2. J Immunol 2014;192:1320-31.

36. Fischer R, Marsal J, Guttà C, Eisler SA, Peters N, Bethea JR, et al. Novel strategies to mimic transmembrane tumor necrosis factordependent activation of tumor necrosis factor receptor 2 . Sci Rep 2017;7:6607.

37. He X, Landman S, Bauland SC, van den Dolder J, Koenen HJ, Joosten I. A TNFR2-agonist facilitates high purity expansion of human low purity Treg cells. PLoS One 2016;11:e0156311.

38. Salomon BL, Leclerc M, Tosello J, Ronin E, Piaggio E, Cohen JL. Tumor necrosis factor $\alpha$ and regulatory T cells in oncoimmunology. Front Immunol 2018;9:444.

39. Chopra M, Riedel SS, Biehl M, Krieger S, von Krosigk V, Bäuerlein CA, et al. Tumor necrosis factor receptor 2-dependent homeostasis of regulatory $\mathrm{T}$ cells as a player in TNF-induced experimental metastasis. Carcinogenesis 2013;34:1296-303.

40. Kampan NC, Madondo MT, McNally OM, Stephens AN, Quinn MA, Plebanski M. Interleukin 6 present in inflammatory ascites from advanced epithelial ovarian cancer patients promotes tumor necrosis factor receptor 2-expressing regulatory T cells. Front Immunol 2017;8:1482.

41. Nadkarni S, Mauri C, Ehrenstein MR. Anti-TNF-alpha therapy induces a distinct regulatory $\mathrm{T}$ cell population in patients with rheumatoid arthritis via TGF-beta. J Exp Med 2007;204:33-9.

42. Nguyen DX, Ehrenstein MR. Anti-TNF drives regulatory T cell expansion by paradoxically promoting membrane TNF-TNF-RII binding in rheumatoid arthritis. J Exp Med 2016;213:1241-53.

43. Schmidt EM, Davies M, Mistry P, Green P, Giddins G, Feldmann $\mathrm{M}$, et al. Selective blockade of tumor necrosis factor receptor I inhibits proinflammatory cytokine and chemokine production in human rheumatoid arthritis synovial membrane cell cultures. Arthritis Rheum 2013;65:2262-73.

44. McCann FE, Perocheau DP, Ruspi G, Blazek K, Davies ML, Feldmann $M$, et al. Selective tumor necrosis factor receptor I blockade is antiinflammatory and reveals immunoregulatory role of tumor necrosis factor receptor II in collagen-induced arthritis. Arthritis Rheumatol 2014;66:2728-38.

45. Ma HL, Napierata L, Stedman N, Benoit S, Collins M, NickersonNutter C, et al. Tumor necrosis factor alpha blockade exacerbates murine psoriasis-like disease by enhancing Th17 function and decreasing expansion of Treg cells. Arthritis Rheum 2010;62:430-40.

46. Jung MK, Kwak JE, Shin EC. IL-17A-producing Foxp3(+) regulatory $\mathrm{T}$ cells and human diseases. Immune Netw 2017;17:276-86.

47. Sakaguchi S, Vignali DA, Rudensky AY, Niec RE, Waldmann H. The plasticity and stability of regulatory T cells. Nat Rev Immunol 2013;13:461-7.

48. Wohlfert E, Belkaid Y. Plasticity of T reg at infected sites. Mucosal Immunol 2010;3:213-5.

49. Dominguez-Villar M, Baecher-Allan CM, Hafler DA. Identification of T helper type 1-like, Foxp3+ regulatory T cells in human autoimmune disease. Nat Med 2011;17:673-5.

50. McClymont SA, Putnam AL, Lee MR, Esensten JH, Liu W, Hulme MA, et al. Plasticity of human regulatory T cells in healthy subjects and patients with type 1 diabetes. J Immunol 2011;186:3918-26.

51. Barbi J, Pardoll D, Pan F. Treg functional stability and its responsiveness to the microenvironment. Immunol Rev 2014;259:115-39.

52. Beriou G, Costantino CM, Ashley CW, Yang L, Kuchroo VK, Baecher-Allan C, et al. IL-17-producing human peripheral regulatory T cells retain suppressive function. Blood 2009;113:4240-9.

53. Du R, Zhao H, Yan F, Li H. IL-17+Foxp3+ T cells: an intermediate differentiation stage between Th17 cells and regulatory T cells. J Leukoc Biol 2014;96:39-48. 
54. Duarte JH, Zelenay S, Bergman ML, Martins AC, Demengeot J. Natural Treg cells spontaneously differentiate into pathogenic helper cells in lymphopenic conditions. Eur J Immunol 2009;39: 948-55.

55. Hovhannisyan Z, Treatman J, Littman DR, Mayer L. Characterization of interleukin-17-producing regulatory T cells in inflamed intestinal mucosa from patients with inflammatory bowel diseases. Gastroenterology 2011;140:957-65.

56. Pesenacker AM, Broady R, Levings MK. Control of tissue-localized immune responses by human regulatory T cells. Eur J Immunol 2015;45:333-43.

57. Whibley N, Maccallum DM, Vickers MA, Zafreen S, Waldmann H, Hori S, et al. Expansion of Foxp3(+) T-cell populations by Candida albicans enhances both Th17-cell responses and fungal dissemination after intravenous challenge. Eur J Immunol 2014;44:1069-
83.

58. Walter GJ, Evans HG, Menon B, Gullick NJ, Kirkham BW, Cope $\mathrm{AP}$, et al. Interaction with activated monocytes enhances cytokine expression and suppressive activity of human CD4+CD45ro+ CD25+CD127(low) regulatory T cells. Arthritis Rheum 2013;65: 627-38.

59. Biton J, Semerano L, Delavallée L, Lemeiter D, Laborie M, Grouard-Vogel G, et al. Interplay between TNF and regulatory T cells in a TNF-driven murine model of arthritis. J Immunol 2011; 186:3899-910.

60. Grinberg-Bleyer Y, Saadoun D, Baeyens A, Billiard F, Goldstein JD, Grégoire S, et al. Pathogenic T cells have a paradoxical protective effect in murine autoimmune diabetes by boosting Tregs. J Clin Invest 2010;120:4558-68. 